\title{
Adenine Nucleotide Catabolism in the Human Trophoblast Early and Late in Gestation ${ }^{1}$
}

\author{
KIM VETTENRANTA AND KARI O. RAIVIO
}

Children's Hospital, University of Helsinki, SF-00290, Finland

\begin{abstract}
Trophoblastic cells were separated and cultured from human first trimester and term placentae for studies on energy metabolism. Changes in the catabolism of prelabeled adenine nucleotides and the adenylate energy charge (EC) were followed during energy deprivation. EC was $0.70 \pm 0.04$ (mean $\pm \mathrm{SD}$ ) in the first trimester and $0.65 \pm 0.08$ in the term cells before experiments. Both during hypoxia ( $\mathrm{N}_{2}$-atmosphere) and in the absence of glucose, ATP and EC were preserved for up to $8 \mathrm{~h}$. 2Deoxyglucose caused a fall in ATP to $12.1 \pm 5.0$ and 14.8 $\pm 7.4 \%$ of initial levels, and in EC to $0.46 \pm 0.04$ and 0.42 \pm 0.05 in the first trimester and term cells, respectively. In first trimester cells, inhibition of oxidative phosphorylation by rotenone in the absence of glucose resulted in a significantly slower reduction of ATP and EC than after deoxyglucose, whereas in term cells, the initial responses were similar. Of total adenine nucleotides degraded, 7.1$10.5 \%$ were released extracellularly as adenosine, when its deamination was inhibited. Human trophoblast appears to tolerate transient hypoxia or deprivation of exogenous glucose. Susceptibility to energy deprivation increases with gestational age. The main pathway for AMP-catabolism is deamination, but the trophoblast is able to produce adenosine during accelerated adenine nucleotide catabolism. (Pediatr Res 24: 373-379, 1988)
\end{abstract}

\section{Abbreviations}

EC, adenylate energy charge

MEM, minimum essential medium

FBS, fetal bovine serum

IMP, inosine 5'-monophosphate

The human placenta appears to consume up to $60 \%$ of the glucose $(1,2)$ and $20 \%$ of the oxygen (3) delivered to the fetoplacental unit. Both are used at high rates to meet the energy requirements of a multitude of synthetic and transport functions. Reduction in availability of glucose or oxygen will result in impairment of placental functions $(4,5)$. Toward the end of pregnancy, both the growth and synthetic functions of the placenta decrease, gross and microscopic vascular abnormalities become common, and disturbances in fetal oxygen and substrate supply are frequent (6).

The effects of oxygen and glucose deprivation on human placental metabolism have been studied in vitro using organ

Received February 25, 1988; accepted May 24, 1988.

Correspondence and reprints Kim Vettenranta, M.D., Children's Hospital, University of Helsinki, Stenbäckinkatu 11, Helsinki, SF-00290 Finland.

Supported by the Sigrid Juselius Foundation, the Foundation for Pediatric Research, and the Finnish Cultural Foundation.

Presented in part at the annual meeting of the European Society for Pediatric Research, Padua, September 6-10, 1987 culture, perfusion, and serial samples of newly delivered, unperfused placental tissue. During hypoxia placental anaerobic glycolysis is activated, as evidenced by increased uptake and consumption of glucose and production of lactate $(2,4,7-12)$. Stores of glycogen, which are present in placental tissue throughout pregnancy, are well preserved, when exogenous glucose can be used in accelerated glycolysis $(2,7)$. However, substantial glycogenolysis takes place during hypoxia, when availability of free glucose is limited $(5,11,13)$. Despite the increase in ATP production through anaerobic glycolysis, tissue ATP and total adenine nucleotides decrease under these circumstances. The EC also declines from the normal range of $0.70-0.81$ to $0.55-0.71$ $(2,7-9,12-14)$.

The human placenta seems able to maintain major energyrequiring processes (lipid and steroid synthesis, amino acid accumulation, etc.) and a stable carbohydrate metabolism for several hours by anaerobic glycolysis alone $(2,4,5,11)$. When activity of glycolysis is decreased, these processes are rapidly impaired $(5,7)$.

The effects of energy substrate deprivation on the metabolically most active part of the placenta, the trophoblast, cannot be reliably judged on the basis of the studies referred to, because the trophoblast constitutes only about $13-15 \%$ of term placental weight (15).

It has also been shown that acute hypoxia enhances production of vasodilatatory prostaglandins in human placenta (16), and that adenosine is released from perfused tissue during ischemia (17). However, blood flow autoregulation reactive to hypoxia or other stimuli has not been demonstrated in human placenta.

We used enzymatic dispersion of placental tissue followed by density gradient sedimentation to obtain cultures of trophoblastic cells for this study. Cell types were identified by staining for intermediate filaments, and specific function was ascertained by the production of human chorionic gonadotropin.

The aims of our study were 1 ) to evaluate the effects of oxygen and glucose deprivation on the metabolic integrity and adenine nucleotide metabolism in human first trimester and term trophoblastic cells in primary culture, and 2) to assess trophoblastic adenosine production during accelerated adenine nucleotide catabolism.

\section{MATERIALS AND METHODS}

Preparation of cell cultures. Normal first trimester placentae (6-12 gestational wk) were obtained from legal terminations using forceps before vacuum extraction of the remainder of the conceptus. Term placentae (39-41 wk) were obtained from elective caesarean sections. A total of 10 primary cultures was prepared from 20 first trimester, and 14 cultures were prepared from 14 term placentae. None of the mothers had any prepregnancy or obstetric problems known to cause placental insufficiency. The placentae were obtained from the Departments of Obstetrics and Gynecology, University of Helsinki, Finland, following approval of the ethical committee of the hospital. 
In preparation of the cultures, we used a modification of our previously described method (18). Briefly, first trimester villous tissue was incubated in MEM [Eagle's modification, with Hanks' salts and $25 \mathrm{mM}$ sulfonic acid (HEPES), without L-glutamine, pH 7.4, Gibco Europe, Paisley, Scotland], containing 0.1\% collagenase (type IV, Sigma Chemical, St. Louis, MO), $0.06 \%$ hyaluronidase (Sigma), $0.01 \%$ soybean trypsin inhibitor (Sigma), and $0.001 \%$ deoxyribonuclease (type I, Sigma) (enzyme medium) for $5 \mathrm{~min}$ at $37^{\circ} \mathrm{C}$. The enzymatic digestion was repeated three times, and the filtrates were pooled and sedimented at $150 \times \mathrm{g}$ for $5 \mathrm{~min}$ at $4^{\circ} \mathrm{C}$. The cells were resuspended in MEM containing $0.003 \%$ deoxyribonuclease, and allowed to sediment through FBS (heat-inactivated, M.A. Bioproducts, Walkersville, MD) at unit gravity and room temperature for $60 \mathrm{~min}$. The supernatant was discarded, the cells were washed, and resuspended in MEM containing $20 \%$ FBS (dialyzed at $4^{\circ} \mathrm{C}$ for 7 days against $0.9 \%$ $\mathrm{NaCl}$ with daily exchanges to remove purine precursors, e.g. hypoxanthine), and penicillin $(100 \mathrm{IU} / \mathrm{ml})$ plus streptomycin $(100 \mu \mathrm{g} / \mathrm{ml})$ (culture medium). Cells were cultured as suspension on uncoated Petri dishes (diameter $90 \mathrm{~mm}$, Sterilin, Feltham, $\mathrm{UK})$ at $37^{\circ} \mathrm{C}$ in $95 \%$ air- $5 \% \mathrm{CO}_{2}$.

Term villous tissue was incubated in enzyme medium for 20 min. Digestion was repeated three times, and the filtrates were pooled, centrifuged, and sedimented twice through FBS as described above. The cells were resuspended in culture medium and cultured as described above.

Neither the first trimester nor term cells attached to the culture dishes during 2 days. Trophoblastic cells, prepared essentially as described above, have previously been shown not to grow or divide during the first 6 days of primary culture (18).

Staining for intermediate filaments. Cell smears were prepared by centrifuging $100 \mu \mathrm{l}$ of cell suspension in a Shandon Elliott Cytospin centrifuge (Shandon Southern Instruments, Sewickley, PA) at $55 \times g$ for $7 \mathrm{~min}$ at room temperature, fixing in methanol at $-20^{\circ} \mathrm{C}$ for $30 \mathrm{~min}$, and washing twice in phosphate-buffered saline, pH 7.4 (Orion Diagnostica, Espoo, Finland). For double indirect immunofluorescence, the cells were first reacted with polyclonal rabbit anti-vimentin antibodies (19), kindly provided by Dr. Ismo Virtanen, Department of Pathology, University of Helsinki, Finland, followed by fluorescein isothiocyanate-coupled sheep anti-rabbit IgG (N.L. Cappel Laboratories, Malvern, PA), and washed. Thereafter the specimens were reacted with monoclonal mouse anti-cytokeratin antibodies (Labsystems, Helsinki, Finland), followed by tetramethyl rhodamine isothiocyanate-coupled goat anti-mouse IgG (N.L. Cappel). In fluorescence microscopy a Leitz Wetzlar Periplan microscope was used.

Preincubation. After $24 \mathrm{~h}$ in culture, both first trimester and term cells were resedimented once through FBS. For labeling of purine nucleotides, cells were resuspended in culture medium containing $\left[8-{ }^{14} \mathrm{C}\right]$ adenine (specific activity $55 \mathrm{mCi} / \mathrm{mmol}$, Amersham International, Amersham, UK) at a final concentration of $100 \mu \mathrm{M}$, and further incubated at $37^{\circ} \mathrm{C}$ in $95 \%$ air-5\% $\mathrm{CO}_{2}$ for $17 \mathrm{~h}$.

Metabolic integrity of cultured cells was monitored in all experiments with the EC (ATP + 1/2ADP/AMP + ADP + ATP) (20) calculated from radioactivity in the nucleotides. Assessment of cell viability using vital dyes (e.g. trypan blue) is not reliable because of the syncytial structure and variable size of the cultured trophoblastic elements.

After prelabeling, the cells were washed twice with phosphatebuffered saline, resuspended in RPMI 1640 medium (GIBCO, Grand Island, NY) containing $25 \mathrm{mM}$ HEPES, pH 7.4, $1 \%$ bovine serum albumin (Sigma), penicillin and streptomycin, but no glucose (incubation medium), and plated onto Nuclon $\mathrm{Mi}$ crotest (Nunc, Roskilde, Denmark) plates.

Preliminary experiments. For experiments in a hypoxic atmosphere, cells in Krebs-Ringer phosphate buffer, $\mathrm{pH} 7.4$, with $5.5 \mathrm{mM}$ D-glucose were placed in a chamber gassed with $100 \%$ $\mathrm{N}_{2}$ for $10 \mathrm{~min}$, then the chamber was tightly sealed, and the cells were incubated at $37^{\circ} \mathrm{C}$ for $8 \mathrm{~h}$. At the end of incubation, the suspension was centrifuged at $150 \times g$, the supernatant was removed, and $0.42 \mathrm{~N}$ perchloric acid was added on the cell pellet on ice. Perchloric acid was also added into the supernatant to a final concentration of $0.42 \mathrm{~N}$. The samples were neutralized with $4.42 \mathrm{~N} \mathrm{KOH}$, and cell extracts were centrifuged at $300 \times g$ for $10 \mathrm{~min}$ to separate acid-insoluble nucleic acids from acid-soluble purine compounds. Samples were stored at $-20^{\circ} \mathrm{C}$.

In another set of preliminary experiments, cells were cultured in incubation medium not containing D-glucose at $37^{\circ} \mathrm{C}$ for $4 \mathrm{~h}$ in $95 \%$ air- $5 \% \mathrm{CO}_{2}$. Termination of experiments, etc. were performed as described above.

Effects of deoxyglucose and rotenone. Cells were preincubated for $60 \mathrm{~min}$ in the absence or presence of $2 \mu \mathrm{M}$ deoxycoformycin (National Cancer Institute, Bethesda, MD) to inhibit adenosine deaminase (21).

The medium was then replaced by incubation medium containing no D-glucose but either $5.5 \mathrm{mM}$ 2-deoxy-D-glucose or $100 \mathrm{nM}$ rotenone (both from Sigma) with or without $2 \mu \mathrm{M}$ deoxycoformycin, depending on the conditions of preincubation. Incubations were continued for $30,60,120$, or $240 \mathrm{~min}$ at $37^{\circ} \mathrm{C}$ in $95 \%$ air $-5 \% \mathrm{CO}_{2}$, terminated, etc. as described above.

In experiments involving inhibition of oxidative phosphorylation, control cultures containing $100 \mathrm{nM}$ rotenone and $5.5 \mathrm{mM}$ D-glucose were also included.

Thin-layer chromatography. Purine nucleotides were separated on polyethyleneimine cellulose thin layer plates (Macherey-Nagel, Düren, FRG) with a stepwise formate gradient as previously described (22). Purine nucleosides and bases were separated from each other and nucleotides using a modification of a previously described method (22). Briefly, we used $10 \times 10 \mathrm{~cm}$ pieces of plates and developed them first in butanol:methanol: water:ammonia (60:20:20:1) and in the second dimension acetonitrile:0.1 N ammonium acetate, pH 7.0:ammonia (60:30:10). Spots representing separated purine compounds were visualized under UV light, cut out from the chromatogram sheets, and counted in $5 \mathrm{ml}$ of Aquasol (New England Nuclear, Boston, MA) using a Wallac Ultrobeta 1210 liquid scintillation counter (LKB Wallac, Turku, Finland). Radioactivity in the nucleic acids was measured by counting the acid-insoluble pellet.

Other analyses. The concentrations of the $\beta$-subunit of human chorionic gonadotropin in culture media were assayed using the method of Pettersson et al. (23). Protein was measured as previously described (24).

Statistical analysis. All experiments were performed in duplicate. Comparison of a single parameter between two groups was performed using the Mann-Whitney U test (nonparametric). All results are expressed as mean $\pm \mathrm{SD} / \mathrm{mg}$ of cell protein. Calculation of actual cell numbers in cultured cell suspensions could not be reliably performed due to the syncytial structure of the majority of cultured trophoblastic elements.

\section{RESULTS}

Characterization of cultured cell population. The primary, short-term cultures obtained from first trimester and term placentae consisted of single cells, cell aggregates, and syncytial elements free from red blood cells and cell debris. Trophoblastic cells were approximated to constitute more than $95 \%$ of the cell population in the four first trimester and five term cultures studied. This was evidenced by the uniform presence of cytokeratin-type intermediate filaments in the cytoskeleton of these epithelial cells (Fig. 1A). Occasional single mesenchymal cells, not expressing cytokeratin- but vimentin-type of intermediate filaments, could be seen (Fig. $1 B$ ).

As a sign of specialized function, the production of human chorionic gonadotropin peaked at $650 \pm 280 \mathrm{IU} / \mathrm{mg}$ protein $(n$ $=4)$ in the first trimester and $1.35 \pm 1.20 \mathrm{IU} / \mathrm{mg}$ protein $(n=$ 6 ) in term cultures during the first $24 \mathrm{~h}$. Thereafter the production steadily declined toward the end of primary culture, as described previously (18). 

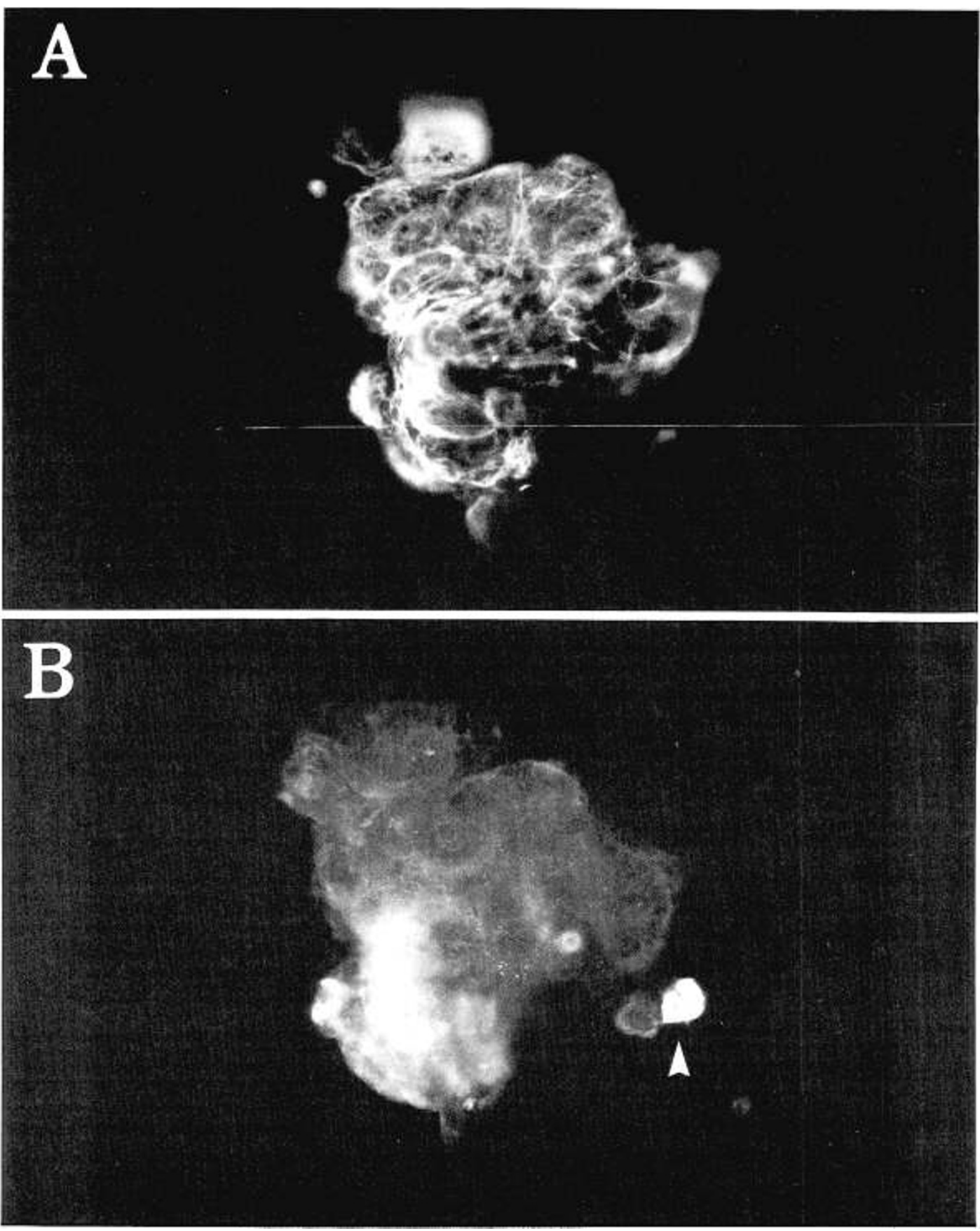

Fig. 1. Cultured trophoblastic cells contain a bright fibrillar cytoplasmic fluorescence after staining with anti-cytokeratin antibodies $(A)$. In double indirect immunofluorescence staining, one mesenchymal cell not containing cytokeratin- but a bright vimentin-specific fluorescence can be seen (arrowhead, B). Diffuse, nonspecific fluorescence can be seen on the rest of the cells in $B . \times 403$.

Preincubation and controls. ${ }^{14} \mathrm{C}$-adenine was incorporated into adenine nucleotides significantly $(p<0.001)$ more in first trimester than in term cells $(29.1 \pm 11.7$ and $2.8 \pm 2.5 \mathrm{nmol} / \mathrm{mg}$ protein, respectively) ( $n=10$ in both groups). Less than $5 \%$ of the incorporated radioactivity was found in nucleic acids. No labeled adenosine or nucleotides were present extracellularly. After preincubation, EC was $0.70 \pm 0.04$ in the first trimester and $0.65 \pm 0.08$ in term cells. These values are not significantly different from those $(0.70-0.81)$ observed in fresh placentae delivered through elective caesarean section (7, 12). Absence of labeled extracellular nucleotides was further evidence for metabolic integrity of the cultured trophoblastic cells.

When prelabeled cells were further incubated for $4 \mathrm{~h}$ in fresh medium containing $5.5 \mathrm{mM}$ glucose, radioactive ATP, and total adenine nucleotides decreased to $43.3 \pm 15.7 \%,(n=10)$ and $48.1 \pm 12.7 \%$ of their initial values in the first trimester and 74.9 $\pm 25.0 \%(n=10)$ and $70.1 \pm 22.4 \%$ in the term cells, respectively. This was probably explained by dilution of the labeled nucleotide 
pool by newly synthesized, unlabeled material. The decrease was significantly $(p<0.05)$ larger in the first trimester than in term trophoblastic cells, which suggests a more rapid nucleotide turnover during the first trimester. No radioactive nucleotides were detected extracellularly. IMP remained stable, and no adenosine was released. Of the radioactivity lost from adenine nucleotides $83.7 \pm 12.6 \%$ were recovered extracellularly as hypoxanthine in the first trimester and $81.8 \pm 26.6 \%$ in the term cultures. Metabolic integrity, as reflected in the phosphorylated state of adenine nucleotides, was preserved under these conditions; the final EC values were $0.71 \pm 0.05$ and $0.66 \pm 0.08$ in the first trimester and term cultures, respectively.

Preliminary experiments. The effects of oxygen deprivation in the presence of glucose, and those of glucose deprivation in the presence of oxygen, on adenine nucleotide metabolism and EC were assessed.

Absence of oxygen ( $100 \% \mathrm{~N}_{2}$ atmosphere) in the presence of glucose had no effect on cellular energy status in term trophoblastic cells. EC remained at $0.81 \pm 0.11(n=4)$ (controls 0.82 $\pm 0.10)$ and labeled intracellular adenine nucleotides declined only to $46.0 \pm 13.9 \%$ (controls $49.4 \pm 11.0 \%$ ) of their initial values during $8 \mathrm{~h}$ of incubation.

In the absence of exogenous glucose but in the presence of oxygen, EC remained at $0.68 \pm 0.05(n=5)$ (controls with glucose $0.71 \pm 0.05)$ in the first trimester and $0.63 \pm 0.12(n=$ 5 ) (controls $0.66 \pm 0.08$ ) in the term cells. Reduction in labeled intracellular adenine nucleotides was similar under glucose-deprived and control conditions in the first trimester cells (to 41.4 \pm 22.7 and $48.1 \pm 12.7 \%$, respectively). In the term cells, however, the reduction was larger in the absence than in the presence of glucose (to $32.7 \pm 9.6$ and $70.1 \pm 22.4 \%$, respectively).

Both first trimester and term trophoblastic cells thus appeared to be able to maintain adequate production of ATP with anaerobic glycolysis alone and to tolerate absence of exogenous glucose for at least $8 \mathrm{~h}$.

Effects of deoxyglucose. In both first trimester and term trophoblastic cells deoxyglucose caused a rapid decline in ATP to $15.9 \%(n=5)$ and $22.8 \%(n=5)$ of initial values, respectively (Fig. $2 A$ and $B$ ). Total adenine nucleotides were also significantly $(p<0.01)$ reduced to $31.6 \pm 6.7$ and $39.2 \pm 10.9 \%$, respectively. Some accumulation of AMP took place simultaneously (Fig. 3 $A$ and $B$ ). These changes were accompanied by a significant ( $p$ $<0.05)$ increase in IMP. In both first trimester and term cells
EC also rapidly decreased (Fig. $4 A$ and $B$ ). A slight but not significant recovery in $\mathrm{EC}$ was seen toward the end of the experiments. The overall changes in EC were parallel in the first trimester and term trophoblastic cells under these circumstances.

Intracellular AMP can be dephosphorylated by cytoplasmic 5'-nucleotidase (E.C. 3.1.3.5) to adenosine or deaminated by AMP-deaminase (E.C. 3.5.4.6) to IMP. In the absence of the adenosine deaminase inhibitor, deoxycoformycin, no accumulation of adenosine took place. In the presence of deoxycoformycin, however, adenosine gradually accumulated extracellularly (Fig. $5 A$ and $B$ ). Adenine nucleotide catabolism was otherwise not affected by deoxycoformycin. Adenosine accounted for $9.7 \pm 6.6 \%$ and hypoxanthine for $83.9 \pm 15.7 \%$ of total adenine nucleotides degraded in the first trimester and for $9.8 \pm 3.8 \%$ and $82.7 \pm 17.3 \%$ in the term cultures, respectively. No labeled nucleotides were shed into the culture medium.

Effects of deoxyglucose in the presence of D-glucose were not studied, because D-glucose largely prevents the induction of adenine nucleotide catabolism by deoxyglucose (25).

Effects of rotenone in the absence of glucose. Blocking mitochondrial electron transport with rotenone resulted in rapid breakdown of ATP. In first trimester $(n=5)$ cells, the initial decline was significantly $(p<0.05)$ slower than that observed in the presence of deoxyglucose (Fig. $2 A)$. In term $(n=5)$ cells initial reductions induced by deoxyglucose and rotenone were parallel, but the latter ended up at a significantly $(p<0.05)$ lower level (Fig. 2B). In early trophoblast, reduction in total adenine nucleotides paralleled that in ATP, and the increase in AMP was slow (Fig. $3 A$ ). In late trophoblast, the initial changes in both adenine nucleotides (a decrease to $41.5 \pm 13.2 \%$ ) and AMP (Fig. $3 B$ ) followed the pattern observed in the presence of deoxyglucose. Eventual reduction in adenine nucleotides to 12.1 $\pm 4.8 \%$ of the initial value was, however, significantly $(p<0.05)$ larger, and increase in AMP slightly more pronounced than in the presence of deoxyglucose.

Increases in IMP by $44.1 \pm 30.0$ and $110.8 \pm 97.9 \%$ in the first trimester and by $120.6 \pm 77.6$ and $292.1 \pm 175.0 \%$ in the term cells in the presence of either deoxyglucose or rotenone, respectively, appeared larger than the elevations in AMP. Interplacental variation in intracellular IMP accumulation was, however, substantial in all experiments.

Inhibition of oxidative phosphorylation caused a progressive reduction in EC. In the first trimester cells, the reduction was significantly $(p<0.01)$ slower than that caused by deoxyglucose
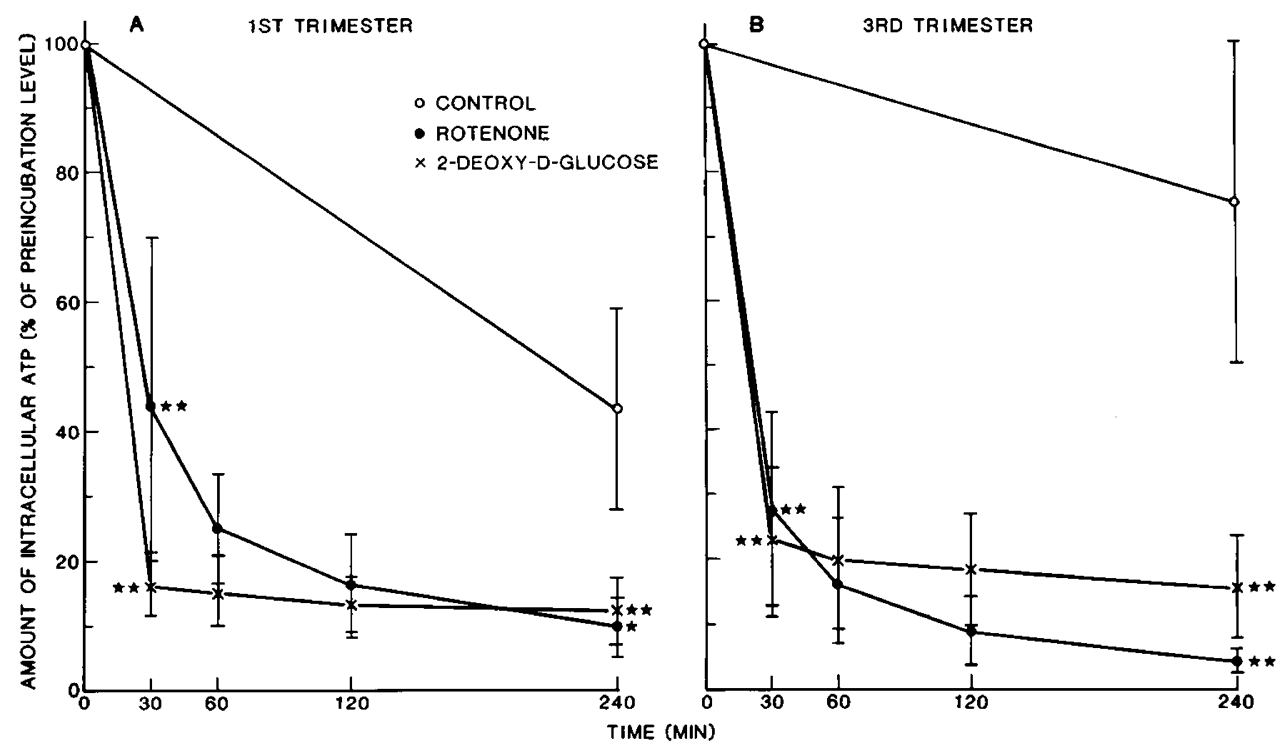

Fig. 2. Reduction in intracellular radioactive ATP as percent of initial value in the first trimester $(A)$ and term $(B)$ trophoblastic cells under control conditions, and in the presence of either deoxyglucose or rotenone. Statistical significance has been tested against the initial value at 30,60 , and $120 \mathrm{~min}$, and against controls at $240 \mathrm{~min} . p<0.01\left(^{* *}\right), p<0.05\left(^{*}\right)$. Values represent mean $\pm \mathrm{SD}$ from a total of 20 experiments. 


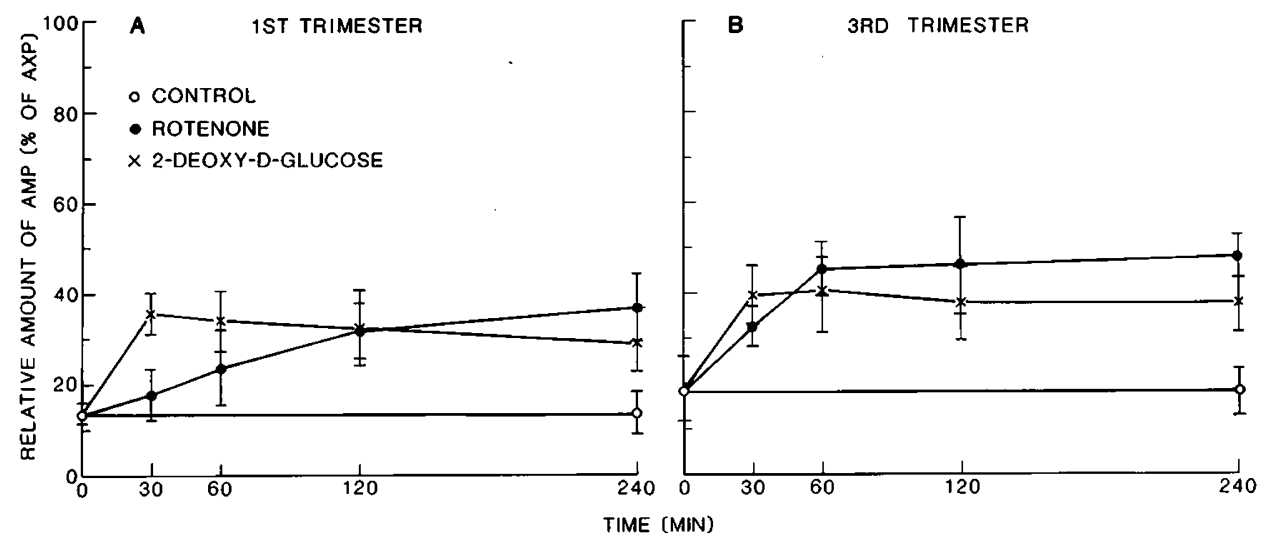

Fig. 3. Relative amount of AMP as percent of total adenine nucleotides $(A X P)$ in the first trimester $(A)$ and term $(B)$ trophoblastic cells under control conditions and in the presence of either deoxyglucose or rotenone. Values represent mean \pm SD from a total of 20 experiments.

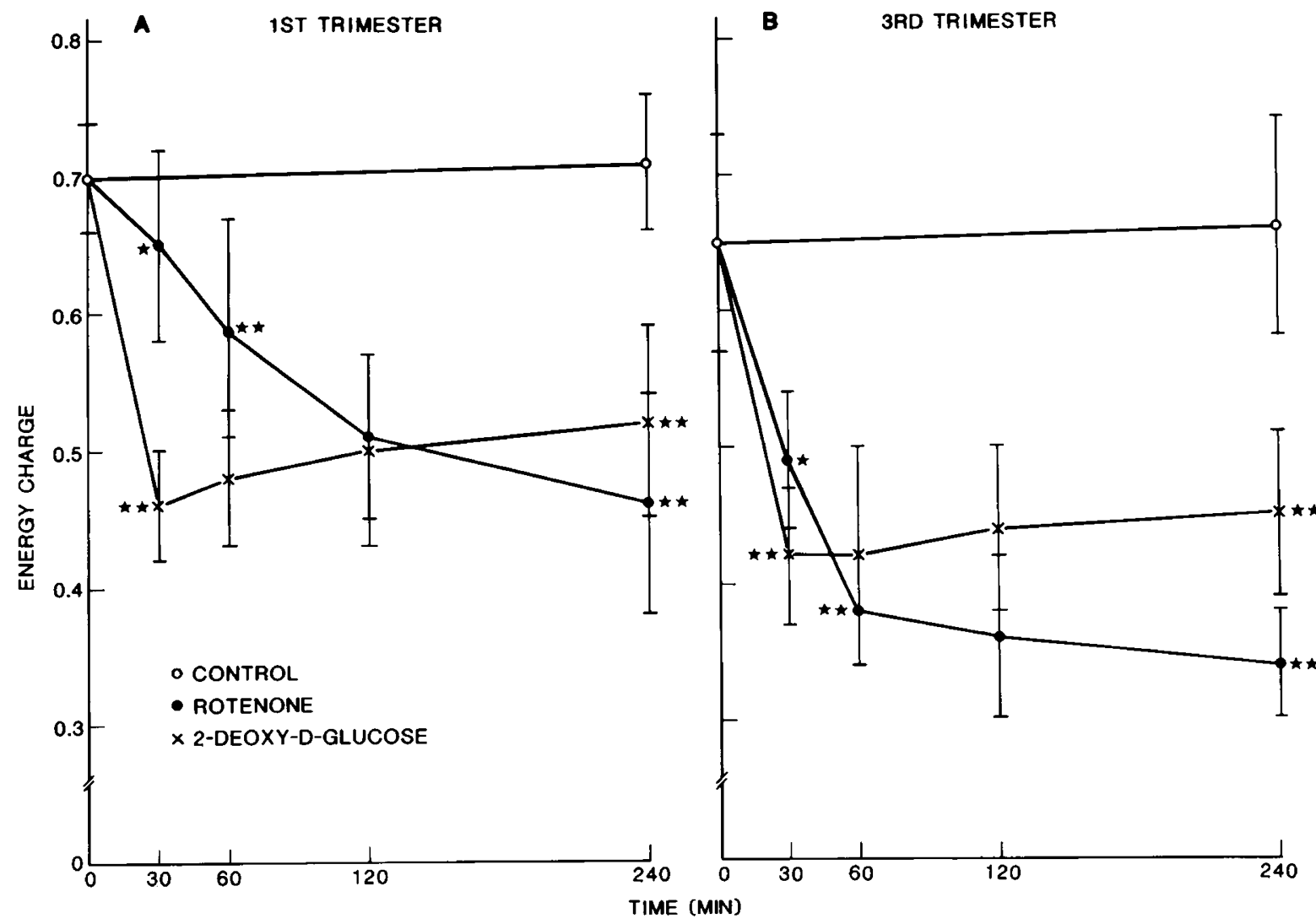

Fig. 4. The EC in the first trimester $(A)$ and term $(B)$ trophoblastic cells under control conditions and in the presence of either deoxyglucose or rotenone. Statistical significance tested and presented as in Figure 2.

(Fig. 4A). In term trophoblastic cells, initial impairment of EC was parallel but the final level significantly $(p<0.05)$ lower after rotenone than after deoxyglucose (Fig. $4 B$ ). The overall effect of rotenone on EC in term cells significantly $(p<0.05)$ exceeded that in first trimester cells.

Rotenone caused no accumulation of labeled adenosine in the absence of adenosine deaminase inhibition. In the presence of deoxycoformycin, extracellular accumulation of adenosine was not significantly different from that observed in the presence of deoxyglucose (Fig. $5 A$ and $B$ ). Of total adenine nucleotides degraded $7.1 \pm 2.7$ and $84.6 \pm 6.2 \%$ were recovered extracellularly as adenosine and hypoxanthine in the first trimester and $10.5 \pm 4.2$ and $79.9 \pm 9.1 \%$ in the term cultures, respectively. Again, deoxycoformycin had no effect on the rate of adenine nucleotide catabolism, and no labeled nucleotides were present extracellularly.
In the presence of glucose, rotenone had no significant effect on $\mathrm{EC}$ in the first trimester $(0.67 \pm 0.04$, controls $0.71 \pm 0.05)$ or in the term cells $(0.67 \pm 0.07$, controls $0.68 \pm 0.09)$. Intracellular ATP declined to $33.3 \pm 9.8 \%$ (controls $43.3 \pm 15.7 \%$ ), and $60.1 \pm 10.4 \%$ (controls $74.9 \pm 25.0 \%$ ), respectively.

Significant formation of radioactive uric acid was not detected in any of the experiments. The $\mathrm{pH}$ of incubation media remained at 7.35-7.40 during all experiments.

\section{DISCUSSION}

Studies on energy metabolism using short-term cultures of human trophoblastic cells have not previously been reported. Our experience indicates that these cultures are a useful model for studies on factors or experimental conditions suspected of 


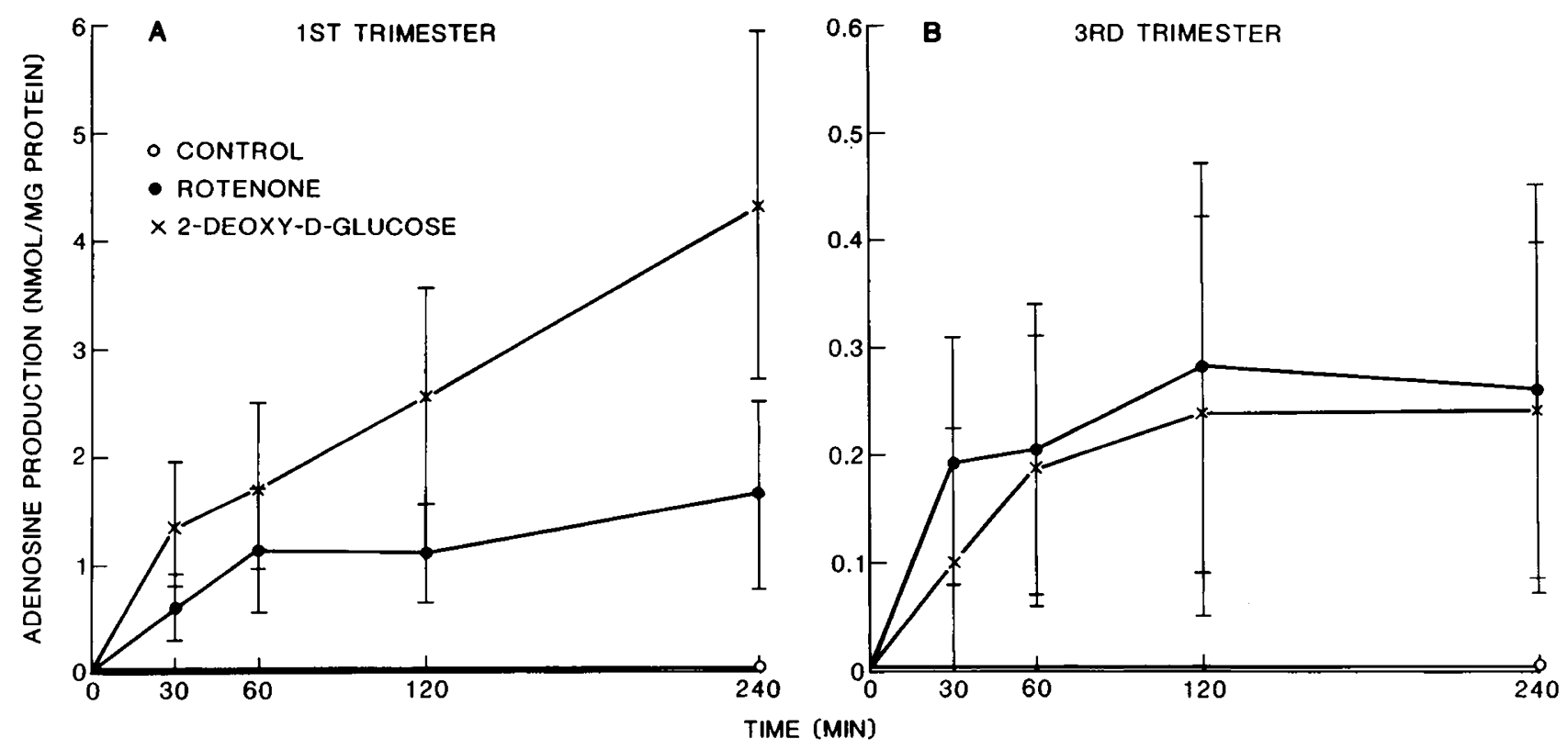

Fig. 5. Extracellular accumulation of radioactive adenosine during adenine nucleotide catabolism in the presence of adenosine deaminase inhibition in the first trimester $(A)$ and term $(B)$ cultures. Values represent mean \pm SD from a total of 20 experiments.

adverse effects on the metabolic integrity of the human trophoblast.

Radioactivity in nucleotides has been widely used to monitor changes in the total amounts of intracellular nucleotides. These studies have shown that labeled and non-labeled ATP are not compartmentalized within cells, radioactivity in nucleotides reflects actual molar concentrations, and labeled and nonlabeled ATP break down at similar rates on induced nucleotide catabolism (25-27).

Trophoblastic energy metabolism. The human placenta is characterized by a high glucose utilization rate $(0.4-0.5 \mu \mathrm{mol} / \mathrm{min} /$ g) (1). Glycolysis has been reported to account for as much as 70 and $90 \%$ of total glucose utilization in the first and third trimester placentae, respectively (28).

Dependence of trophoblastic energy status on a high rate of glycolytic ATP production is consistent with our findings that a rapid and irreversible reduction in intracellular ATP and deterioration of EC occur in the presence of deoxyglucose. In addition to inhibition of glycolysis, this compound induces ATP depletion through a decrease in intracellular inorganic phosphate (33).

Although about $20 \%$ of placental glucose utilization occurs aerobically, oxidative phosphorylation appears to produce more than $80 \%$ of ATP under normal circumstances $(1,2)$. However, during hypoxia anaerobic glycosis seems capable of maintaining the metabolic integrity of the trophoblast $(2,4,5)$. This is supported by our observations that ATP and EC are preserved in trophoblastic cells subjected to hypoxia in the presence of glucose.

We also found that the metabolic integrity of the cultured cells did not deteriorate in the absence of exogenous glucose. The human placenta contains glycogen as well as possesses the ability to release glucose-1-phosphate from glycogen throughout gestation (13). Ability of the placenta to respond to an increased demand for glucose with enhanced glycogenolysis has also been demonstrated previously $(5,11,13)$.

Experiments performed in the presence of rotenone and in the absence of glucose show that an increased demand for ATP production through anaerobic glycolysis, in the face of decreased availability of substrate, results in rapid impairment of trophoblastic energy status. Under these circumstances, reductions in ATP, adenine nucleotides, and EC were slower in the first trimester than in term trophoblastic cells. This may be due to the substantially larger stores of glycogen in the first trimester trophoblast (29).

Increase in anaerobic glycolysis and deterioration of cellular energy status have been reported in ischemic placental tissue after birth $(7,9,12)$. Concentrations of ATP, total adenine nucleotides, and the EC were reduced by $35-60 \%, 10-30 \%$, and $15-20 \%$, respectively, during $20-80 \mathrm{~min}$ of ischemia.

However, conclusions concerning trophoblastic energy metabolism cannot be drawn from studies using randomly sampled, ischemic placental tissue. This is due to difficulties in determination of the duration of ischemia, the availability of glucose and oxygen in intervillous blood, the influence of substrate gradients within the unperfused tissue, and the contribution of villous mesenchyme to the changes observed in these studies.

Pathways of adenine nucleotide catabolism in the trophoblast. In the presence of adenosine deaminase inhibition, and either deoxyglucose or rotenone, less than $15 \%$ of the adenine nucleotides catabolized could be recovered as adenosine. Accumulation of AMP was less than that of IMP under these circumstances, and the main purine degradation product was hypoxanthine. The ability of hypoxanthine/guanine phosphoribosyltransferase (E.C. 2.4.2.8) to convert hypoxanthine to IMP has been shown to be drastically reduced under similar circumstances (27). Therefore, the possibility of hypoxanthine contributing to the observed IMP accumulation was considered not significant. Also, the possible effect of purine synthesis de novo on our results was not considered significant, because the ability of the human trophoblast to synthesize purines de novo appears to be extremely limited in vitro even in the presence of ample glucose and oxygen (30).

Thus, the main pathway for AMP catabolism during accelerated adenine nucleotide catabolism seems to be deamination to IMP rather than dephosphorylation to adenosine. This finding is at variance with the previous proposition $(31,32)$ that the bulk of AMP formed in the term placenta during adenine nucleotide catabolism is dephosphorylated rather than deaminated. However, this hypothesis was based solely on apparent activities of enzymes measured in term placental extracts.

Our data also suggest that AMP deamination predominates over dephosphorylation in the presence of both decreasing (deoxyglucose) (33) and increasing (inhibition of oxidative phosphorylation) (34) intracellular concentrations of inorganic phos- 
phate. This is in accordance with the regulatory characteristics of human placental cytoplasmic 5 '-nucleotidase (35). Under physiological conditions the enzyme appears to be regulated mainly by nucleoside $5^{\prime}$-monophosphates, nucleoside di- and triphosphates, and $\mathrm{Mg}^{2+}$, but not by inorganic phosphate. Kinetic properties of this $5^{\prime}$-nucleotidase may also account for the somewhat larger accumulation of IMP compared to AMP, inasmuch as the former has a higher $K_{m}(30 \mu \mathrm{M})$ than the latter $(18 \mu \mathrm{M})$, and the $V_{\max }$ is lower. Kinetic parameters, and particularly the regulatory role of inorganic phosphate, of placental adenylate deaminase are not known.

It has also been shown that the syncytial brush border membrane of human placenta has an active, sodium-dependent transport mechanism for phosphate $\left(K_{m} 162 \mu \mathrm{M}\right.$ at pH 7.5 and in the presence of $100 \mathrm{mM}$ sodium). This mechanism was proposed to be responsible for the maternal-fetal gradient of phosphate (36), and it appears to be saturated under our experimental conditions. High intracellular concentration of inorganic phosphate may be the cause of the seemingly minor role for phosphate in the regulation of trophoblastic purine nucleotide catabolism.

Trophoblastic production of adenosine. Evidence for a role for adenosine in the regulation of coronary, cerebral, and hepatic blood flow has recently accumulated (37-39). The presence of high- and low-affinity receptors for adenosine in the human placenta has been established (40), and a vasodilatory effect of adenosine on placental artery and vein has been demonstrated in vitro (41). However, the role of adenosine in placental blood flow autoregulation remains conjectural.

Human placental adenosine kinase (E.C. 2.7.1.20) has a low $K_{m}$ for both adenosine $(0.4 \mu \mathrm{M})$ and $\mathrm{Mg}$ ATP $(75 \mu \mathrm{M})(42)$. We presumed that intracellular ATP did not reach levels this low until during the second half of incubation. Therefore, some rephosphorylation of adenosine to AMP most likely took place at least during the first $120 \mathrm{~min}$.

However, our data indicate that the human trophoblast is able to synthesize and possibly secrete adenosine into the intervillous space and/or villous interstitium during rapid adenine nucleotide catabolism. It remains to be established if adenosine is capable of diffusing through the interstitium and exerting regulatory effects on the fetal vasculature traversing the villous core.

\section{CONCLUSION}

It thus appears that 1 ) the human trophoblast is able to maintain its energy supply during transient hypoxia by anaerobic glycolysis alone, 2) short-term deprivation of exogenous glucose does not adversely affect trophoblastic energy status, 3) the trophoblastic response to interference in its glycolytic production of ATP does not change as a function of gestational age, 4) susceptibility of trophoblastic tissue to deprivation of exogenous glucose and oxygen may increase with gestational age, 5) the main pathway for trophoblastic AMP-catabolism is deamination to IMP, and 6) human trophoblast is able to produce adenosine during accelerated adenine nucleotide catabolism.

Acknowledgments. We thank Ms Ritva Löfman for skillful technical assistance, Drs Ulf-Håkan Stenman and Henrik Alfthan for measuring $\beta$-hCG, and Dr Ralf Bützow for technical contribution.

\section{REFERENCES}

1. Hauguel S, Challier J-C, Cedard L, Olive G 1983 Metabolism of the human placenta perfused in vitro: glucose transfer and utilization, $\mathrm{O}_{2}$ consumption, lactate and ammonia production. Pediatr Res 17:729-732

2. Illsley NP, Aarnoudse JG, Penfold P, Bardsley SE, Coade SB, Stacey TE, Hytten FE 1984 Mechanical and metabolic viability of a placental perfusion system in vitro under oxygenated and anoxic conditions. Placenta 5:213226

3. Challier J-C, Schneider H, Dancis J 1976 In vitro perfusion of human placenta: V. Oxygen consumption. Am J Obstet Gynecol 126:261-265

4. Gabbe SG, Villee CA 1971 The effect of hypoxia on progesterone synthesis by placental villi in organ culture. Am J Obstet Gynecol 111:31-37

5. Longo LD, Yuen P, Gusseck DJ 1973 Anaerobic, glycogen-dependent transport of amino acids by the placenta. Nature 243:531-533

6. Chard T (ed) 1986 The human placenta. Clin Obstet Gynaecol 13:3

7. Bloxam DL, Bobinski PM 1984 Energy metabolism and glycolysis in the human placenta during ischemia and in normal labour. Placenta 5:381-394

8. Bloxam DL, Bullen BE 1986 Condition and performance of the perfused human placental cotyledon. Am J Obstet Gynecol 155:382-388

9. Carroll MJ, Young M 1987 Observations on the energy and redox state and protein synthetic rate in animal and human placentas. J Perinat Med 15:2130

10. Rice PA, Rourke JE, Nesbitt REL Jr 1979 In vitro perfusion studies of the human placenta: VI. Evidence against active glucose transport. Am J Obstet Gynecol 133:649-655

11. Roux JF, Villee CA 1960 Effects of anoxia on the metabolism of the human placenta in vitro. Am J Obstet Gynecol 80:224-228

12. Young MPA, Schneider H 1984 Metabolic integrity of the isolated perfused lobule of human placenta. Placenta 5:95-104

13. Gabbe SG, Demers LA, Greep RO, Villee CA 1972 The effects of hypoxia on placental glycogen metabolism. Am J Obstet Gynecol 114:540-545

14. Krantz KE, Blakey J, Yoshida K, Romito JA 1971 Demonstration of viability of perfused human term placenta. Obstet Gynecol 17:183-191

15. Teasdale $F 1980$ Gestational changes in the functional structure of the human placenta in relation to fetal growth: a morphometric study. Am J Obstet Gynecol 137:560-568

16. Ekblad U, Erkkola R, Uotila P 1987 The effect of acute hypoxia on prostaglandin release in perfused human fetal placenta. Prostaglandins 33:553-560

17. Slegel P, Kitagawa H, Maguire MH 1987 Effect of ischemia on fetal release of adenosine in perfused human placental cotyledons: measurement of adenosine by fluorescence derivatization and HPLC. Fed Proc 46:804(abstr)

18. Vettenranta K, von Koskull H, Heikinheimo M, Raivio KO 1986 Cytoskeletal markers and specific protein production in cells cultured from human first and third trimester placentae. In Vitro Cell Dev Biol 22:100-106

19. Virtanen I, Lehto V-P, Lehtonen E, Vartio T, Stenman S, Kurki P, Wager O Small JV, Dahl D, Badley RA 1981 Expression of intermediate filaments in cultured cells. J Cell Sci 50:45 -63

20. Atkinson DE 1977 Cellular Energy Metabolism and its Regulation. Academic Press, New York

21. Henderson JF, Brox L, Zombor G, Hunting D, Lomax CA 1977 Specificity of adenosine deaminase inhibitors. Biochem Pharmacol 26:1967-1972

22. Crabtree GW, Henderson JF 1971 Rate-limiting steps in the interconversion of purine ribonucleotides in Ehrlich ascites tumor cells in vitro. Cancer Res 31:985-991

23. Pettersson K, Siitari H, Hemmilä I, Soini E, Lövgren $T$, Hänninen V, Tanner P, Stenman U-H 1983 Time-resolved fluoroimmunoassay of human choriogonadotropin. Clin Chem 29:60-64

24. Peterson GL 1977 A simplification of the protein assay method of Lowry et al., which is more generally applicable. Anal Biochem 83:346-356

25. Lomax CA, Bagnara AS, Henderson JF 1975 Studies of the regulation of purine nucleotide catabolism. Can J Biochem 53:231-241

26. Lomax CA, Henderson JF 1973 Adenosine formation and metabolism during adenosine triphosphate catabolism in Ehrlich ascites tumor cells. Cancer Res 33:2825-2829

27. Matsumoto SS, Raivio KO, Seegmiller JE 1979 Adenine nucleotide degradation during energy depletion in human lymphoblasts: adenosine accumulation and adenylate energy charge correlation. J Biol Chem 254:8956-8962

28. Sakurai T, Tagaki H, Hosoya N 1969 Metabolic pathways of glucose in human placenta. Am J Obstet Gynecol 105:1044-1054

29. McKay DG, Hertig AT, Adams EC, Richardson MV 1958 Histochemical observations on the human placenta. Obstet Gynecol 12:1-36

30. Vettenranta K 1988 Pathways of purine nucleotide synthesis in the human trophoblast early and late in gestation. J Dev Physiol (in press)

31. Maguire MH, Aronson DM 1981 Measurement of human placental 5'-AMP deaminase activity by radiometric assay. Anal Biochem 116:174-180

32. Sim MK, Maguire MH 1972 Presence of adenosine in the human term placenta. Circ Res 31:779-788

33. Sauer LA 1978 Control of adenosine monophosphate catabolism in mouse ascites tumor cells. Cancer Res 38:1057-1063

34. Barankiewicz J, Cohen A 1984 Nucleotide catabolism and nucleoside cycles in human thymocytes. Biochem J 219:197-203

35. Madrid-Marina V, Fox IH 1985 Human placental cytoplasmic 5 '-nucleotidase: kinetic properties and inhibition. J Biol Chem 261:444-452

36. Brunette MG, Allard S 1985 Phosphate uptake by syncytial brush border membranes of human placenta. Pediatr Res 19:1179 1182

37. Berne RM, Knabb RM, Ely SW, Rubio R 1983 Adenosine in the local regulation of blood flow: a brief overview. Fed Proc 42:3136-3142

38. Ezzat WR, Lautt WW 1987 Hepatic arterial pressure-flow autoregulation is adenosine mediated. Am J Physiol 252:H836-H845

39. Morii S, Ngai AC, Ko KR, Winn HR 1987 Role of adenosine in regulation of cerebral blood flow: effects of theophylline during normoxia and hypoxia. Am J Physiol 253:H165-H175

40. Schocken DD, Schneider MN 1986 Use of multiple radioligands to characterize adenosine receptors in human placenta. Placenta 7:339-348

41. Krygicz J, Urban J, Malofiejew M 1978 Influence of adenosine on contractility of isolated vessels of human placenta. Am J Obstet Gynecol 131:587-589

42. Palella TD, Andres CM, Fox IH 1980 Human placental adenosine kinase: kinetic mechanism and inhibition. J Biol Chem 255:5264-5269 